сохранение здоровья является возможным при применении современных, традиционных оздоровительных систем. Регулярная физическая деятельность способна приостановить возрастные изменения физиологических функций. Физическая культура и спорт занимает важное место в учебе, работе, отдыхе.

1. Алексеев, С.В. Физическая культура и спорт в Российской Федерации: новые вызовы современности: Монография / С.В. Алексеев, Р.Г. Гостев, Ю.Ф. Курамшин. -М.: Теор. и практ. физ. культ., 2013. - 780 с.

2. Васенков Н.В., Васенков В.Н., Мишланова В.А. Стретчинг в жизни студента / Наука и образование: новое время. 2018. № 3 (26). С. 505-508.

3. Волков, В. К. Современные и традиционные оздоровительные системы / В. К. Волков // Теория и практика физической культуры. - 1996. - № 12. - С. 7-10.

4. Кеннет Купер. Аэробика для хорошего самочувствия. М.: Физкультура и спорт, 1989. - 224 с.

5. Кобяков, Ю.П. Физическая культура. Основы здорового образа жизни: Учебное пособие / Ю.П. Кобяков. - Рн/Д: Феникс, 2012. - 252 с.

6. Мифтахов Р.А., Хайруллин И.Т., Халиков И.Ю. Методологические основания этнопедагогических традиций в физическом развитии молодежи / Научное обозрение: гуманитарные исследования. 2017. № 5. C. 51-54.

7. Фурманов, А. Г. Оздоровительная физическая культура: учебник для студентов вузов / А.Г. Фурманов, М. Б. Юспа. - Мн.: Тесей, 2003. - 390 с.

8. Хабиров, И.И., Хайруллин, И.Т. Особенности физических упражнений для формирования атлетического телосложения молодого человека. Тенденции развития науки и образования. 2018. № 46.

\title{
Сексенова Л.Ш. ${ }^{1}$, Касымбекова Б.К. ${ }^{1}$, Дедова О.Ю. ${ }^{1}$, Бабаева К.С. ${ }^{2}$,

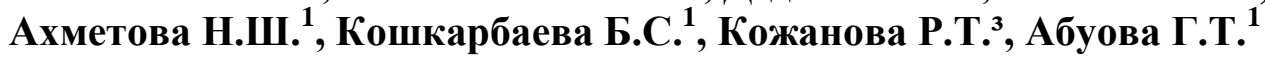 Научно-ориентированное обучение в системе медицинского образования
}

${ }^{1}$ Медицинский университет Караганды (Казахстан, Караганда) ${ }^{2}$ Международный казахско-туречкий многопрофильный университет им. Х.А. Ясави (Казахстан, Туркестан) ${ }^{3}$ Республиканский высший медицинский колледж (Казахстан, Алмать)

doi: $10.18411 / \mathrm{lj}-02-2019-24$

idsp: ljournal-02-2019-24

\section{Аннотация}

В статье представлен опыт внедрения элементов научно- ориентированного обучения в учебный процесс медицинских учебных заведений при проведении практических занятий и самостоятельной работы студентов под руководством преподавателя (СРСП). В течение двух учебных лет в данной работе участвовали 39 кафедр $(73,2 \%)$ трех учебных заведений. Анализ полученных ответов на вопросы анкеты показал, что кафедры пытаются использовать все элементы научноориентированного обучения (НОО) в образовательном процессе как бакалавриата, так и послевузовского образования. Активность участия кафедр при внедрении элементов RBL, обучающих студентов на начальных курсах, не меньше активности выпускающих кафедр.

Ключевые слова: новые технологии в учебном процессе, медицинское образование, научно-ориентированное обучение.

\section{Abstract}

The article presents the experience of introducing elements of the research-based learning (RBL) implementation into the educational process during the practical lessons and student individual work under the observation of a teacher of (SIWT) the medical schools. 39 $(73,2 \%)$ departments from three educational participated at this work in during two academic years. The analysis of the questionnaire answers showed that the departments are trying to use all elements of research-based learning (RBL) in the educational process of bachelor and 
postgraduate education programms. The active participation of the departments in the introduction of elements of research-based learning (RBL) are teaching students elementary level, not less the active graduating of departments.

Keywords: new technologies in educational process, medical education, researchbased learning

В настоящее время в каждой отрасли государства происходит глубокая и постепенная модернизация, в том числе и в образовательном секторе. Поэтому сегодня при подготовке специалистов в медицинских необходимы коренные изменения в стратегии и тактике обучения [1]. Поэтому качественная подготовка медицинских кадров является актуальной задачей системы образования в Республике Казахстан, которая предусматривает внедрение новых технологий и методов в учебный процесс. Одним из новых методов является научно-оиентированное (исследовательское) обучение (HOO) или research-based learning (RBL), которое базируется на научноинновационной ориентации будущих специалистов [2,3]. RBL (research based-learning) это более высокий уровень обучения, что предполагает эффективное развитие практических навыков и умений у обучающихся, вовлечение их в самостоятельное выполнение исследований с осознанием механизма изучаемых процессов [4].

Цель исследования. Провести анализ внедрения элементов научноориентированного обучения в учебный процесс Медицинского университета Караганды, Международного казахско-турецкого многопрофильного университета им. Х.А. Ясави и Республиканского высшего медицинского колледжа на основании анкетного опроса преподавателей.

Материал и методы исследования. В течение 2015-2016 и 2016-2017 учебного годов было проведено анкетирование профессорско-преподавательского состава 39 кафедр трех учебных заведений по использованию элементов HOO (RBL) в образовательном процессе. Анкета включала 4 вопроса: 1. Какие элементы научноориентированного обучения Вы используете на занятиях со студентами? 2. Отражено ли проведение RBL в учебно-методическом комплексе (УМКД)? 3. Вовлечены ли студенты в небольшие научно-исследовательские проекты кафедры? 4. Какие трудности возникли при внедрении RBL в учебный процесс по Вашим дисциплинам?

Результаты и обсуждение. Все использованные элементы RBL были отражены в УМКД: рабочих программах, силлабусах, методических указаниях по проведению самостоятельной работы студентов под руководством преподавателя (СРСП) и самостоятельной работы студентов (СРС). Необходимо констатировать тот факт, что активность кафедр повысилась при внедрении элементов RBL в свой учебный процесс. Так если при проведении первого анкетирования (2015-2016 учебный год) всего участвовали $11(8,1 \%)$ кафедр, то в 2016-2017 учебном году в данной работе приняли участие $39(73,2 \%)$ кафедр от общего числа из трех учебных заведений.

Анализ полученных ответов на вопросы анкеты позволил нам сделать определенный вывод о том, что кафедры, в силу своих возможностей, пытаются использовать все векторы научно-ориентированного обучения (RBL) в образовательном процессе как бакалавриата, так и послевузовского образования.

Ответы на вопросы анкеты показали, что практически все кафедры использовали следующие элементы RBL: написание реферата, эссе, резюме, аналитического обзора, аннотации, тезисов, статьи, докладов, отчета, обзора литературы по электронным базам данных). Кроме вышеназванных элементов RBL на кафедрах эпидемиологии и коммунальной гигиены, клинической иммунологии, аллергологии и микробиологии, пропедевтики внутренних болезней, скорой медицинской помощи, фармацевтических дисциплин и химии использовали написание и защиту курсовой работы, подготовку презентаций, проведение мини конференций с выступлением студентов с докладами по результатам самостоятельной работы. Кафедры истории Казахстана и социальнополитических дисциплин активно использовали полевое исследование, куда входят сбор данных, обработка, анализ, оформление полученных результатов, написание 
отчета. Кафедры детских болезней, общей врачебной практики при подготовке резидентов использовали ретроспективный и проспективный анализы пациентов по различным нозологиям. Кафедра клинической фармакологии и доказательной медицины проводили поисковую работу доказательной базы по эффективности и безопасности лекарственных средств.

Анализ вопроса по вовлеченности студентов в небольшие научноисследовательские проекты кафедр, показал, что не на всех кафедрах имеется и ведется финансируемая научно-исследовательская работа, которая позволяла бы вовлекать студентов в исследовательский процесс. Все кафедры, у которых отсутствуют финансируемые исследования, указали, что научная работа, проводимая обучающимися, выполняется в рамках научно-исследовательской работы студентов (НИРС) и студенческого научного общества (CHO), т.е. работа была направлена только на овладение студентами специальных знаний и исследовательских приемов, что не соответствует основной цели НОО, а именно: формированию у будущих специалистов системы здравоохранения аналитического и критического мышления, овладению методами биомедицинских исследований и принципами доказательной медицины.

Анализ трудностей внедрения элементов научно-ориентированного обучения (RBL) в учебный процесс выявил отсутствие единых точных критериев, требований, форм проведения. У преподавательского состава нет достаточных навыков по ведению занятий с использованием RBL. Более глубокий анализ выявил, что ряд кафедр $(7,5 \%)$ отметили в качестве трудностей при внедрении HOO (RBL) следующее: теоретическая направленность кафедры, недостаточная обеспеченность оборудованием и расходными материалами, отсутствие финансовой поддержки со стороны руководства студентов, которые выступают на международных конференциях, короткий цикл занятий, не все студенты охвачены РБЛ, только члены СНО, нет тотального вовлечения студентов, т.к. не может быть RBL на конкретное занятие, нет понятной осмысленной цели данного внедрения у студентов с количеством 1000 человек на курсе (потоке).

Однако не все анкеты содержали исчерпывающие ответы на поставленные вопросы. Ряд кафедр $(4,3 \%)$ не смогли конкретно ответить о формах внедрения элементов $\mathrm{HOO}(\mathrm{RBL})$ в свой учебный процесс.

Резюмируя вышеизложенное, можно сказать, что RBL (research based-learning) это инновационный более высокий уровень обучения. Но, на наш взгляд, необходимо разработать и утвердить единые методологические подходы, которые позволят преподавателям правильно использовать элементы научно-ориентированного обучения (РБЛ) в учебном процессе. При этом, необходимо привлекать преподавателей тех кафедр, которые уже сейчас предпринимают попытки внедрения RBL. Это кафедры русского языка, эпидемиологии и коммунальной гигиены, клинической иммунологии, аллергологии и микробиологии, пропедевтики внутренних болезней, фармацевтических дисциплин и химии, истории Казахстана и социально-политических дисциплин, детских болезней, общей врачебной практики и другие.

Мы также считаем, что необходимо распределить навыки RBL по годам обучения. В свое время, при внедрении НОО в учебный процесс, мы предложили такой вариант распределения [5]. Это позволило последовательно и поэтапно внедрять НОО (РБЛ) в обучение с дифференцированными критериями для каждого года обучения. Наш опыт внедрения RBL в образовательный процесс показал, что элементы HOO всетаки лучше вводить не на уровне НИРС, а на уровне учебно-исследовательской работы (УИРС), т.к. учебный процесс является непрерывным. Для этого, на наш взгляд, лучше всего вводить элементы НОО на занятия СРСП, но с использованием тем СРС, т.к. они наиболее расширенные, и, как правило, имеют проблемный, характер и подход, что более всего соответствует целям и задачам научно-ориентированного обучения [5].

Таким образом, ситуация по внедрению HOO (RBL) в образовательный процесс медицинских учебных заведений неоднозначна и требует всестороннего изучения и глубокого анализа. Представленные доводы в пользу эффективности RBL (research based-learning) - научно-ориентированного обучения, позволяют сделать вывод о том, 
что для реализации поставленных задач необходимы время и, несомненно, доказательная база.

1. Государственная программа развития здравоохранения РК «Саламатты Казахстан» на 2011 - 2015 годы, утвержденная Указом Президента РК от 29 ноября 2010 года № 1113. [Электронный ресурс]. URL: https://online.zakon.kz/document/?doc id=30861087\#pos=0;0 (дата обращения: 24.10.2018).

2. Гринхальх Т. Основы доказательной медицины: Пер. с англ./ Под ред. И.Н. Денисова, К.И. Сайткулова. 3 изд.М.: ГЭОТАР-Медиа, 2008. 288 с.

3. Койков В.В., Дербисалина Г.А. Роль research-based learning в подготовке инновационно-активных специалистов системы здравоохранения // Журнал развития здравоохранения. №4. 2012. С.621-673.

4. Алфёрова М.А., Голубчикова М.Г. Использование современных образовательных технологий. Примерные требования к оформлению материалов: методические рекомендации. Иркутск: Изд-во ГОУ ДПО ИГИУВ, 2008. - 23 с.

5. Кемелова Г.С., Газалиева М.А., Ахметова Н.Ш., Макаренко Т.В., Наджарян Л.К. Научноориентированное обучение в медицинском образовании // Международный журнал прикладных и фундаментальных исследований. 2015. № 12(10). С.1866-1869.

\section{Сидоркина Н.В., Маркелова Т.В. \\ Эффективность применения инновационных технологий в профессионально - ориентированном обучении иностранному языку}

Тольяттинский государственньій университет ГБПОУ «Тольяттинский химико-технологический колледж» (Россия, Тольятти)

doi: $10.18411 / \mathrm{j}-02-2019-25$

idsp: ljournal-02-2019-25

\section{Аннотация}

Актуальность исследования в статье определяется необходимостью анализа эффективности применения инновационных технологий в профессионально ориентированном обучении иностранному языку, поскольку они помогают реализовать личностно-ориентированный подход в обучении, обеспечивают индивидуализацию и дифференциацию обучения с учетом способностей студентов и уровня их подготовки. Инновационные педагогические технологии такие, как обучение в сотрудничестве, проектная методика, информационно-коммуникационные технологии, решающие педагогические проблемы, позволяют организовать профессионально - ориентированное обучение иностранному языку на качественно новом уровне. Цель исследования состоит в обосновании эффективности применения инновационных технологий в профессионально - ориентированном обучении иностранному языку.

Ключевые слова: эффективность, качество, инновационные технологии, профессионально-ориентированное обучение иностранному языку, педагогика сотрудничества, метод проектов.

\section{Abstract}

The relevance of the research in the article is determined by the need to analyze the effectiveness of the use of innovative technologies in vocational-oriented teaching of a foreign language, because they help to realize a student-centered approach to learning, provide for individualization and differentiation of learning, taking into account the students' abilities and their level of training. Innovative pedagogical technologies such as learning in collaboration, project methodology, information and communication technologies that solve pedagogical problems, allow you to organize professionally-oriented foreign language learning at a qualitatively new level. The purpose of the study is to substantiate the effectiveness of the use of innovative technologies in vocational-oriented teaching of a foreign language.

Keywords: efficiency, quality, innovative technologies, vocational-oriented teaching of a foreign language, pedagogy of cooperation, project method. 